\title{
ENGAGEMENT WITH THE INVERTED CLASSROOM APPROACH: STUDENT CHARACTERISTICS AND IMPACT ON LEARNING OUTCOMES
}

\author{
Micah Stickel", Qin $\mathrm{Liu}^{+}$ \\ *Edward S. Rogers, Sr. Department of Electrical and Computer Engineering, University of Toronto \\ ${ }^{+}$Ontario Institute for Studies in Education, University of Toronto \\ m.stickel@utoronto.ca
}

\begin{abstract}
The focus of this paper is to take a closer look at this question of engagement with the inverted classroom approach and specifically address the following two research questions: 1) Do students with different degrees of engagement with the inverted classroom approach exhibit different academic characteristics?, and 2) How does the degree of engagement affect the learning of the course material?
\end{abstract}

To assess these questions, the students preferred learning styles (ILS), their self-efficacy, and their academic performance prior to the course were assessed. As well, the students' engagement with the approach was assessed through their lecture attendance and pre-class video viewing, and their learning was quantified through pre/post concept tests, in-class pop quizzes, and the final course grade.

Using $k$-means clustering with the pre-class viewing and lecture attendance data, the cohort was divided into three groups: high, medium, and low degrees of engagement with the teaching approach. Some differences were noted in terms of the groups' learning styles and prior academic performance, but no differences were found with their self-efficacy scores. Students in the high engagement group did significantly better than their peers in the other two groups, with final course mark averages of $M_{\text {high }}=$ $81.8 \%, M_{\text {medium }}=74.0 \%, M_{\text {low }}=63.5 \%, F(2,323)=67.4$, $p<.001$. When prior academic performance and learning styles were controlled for, in comparison to the low engagement group, being part of the medium or high engagement group was a significant positive predictor for the final course grade, with $\beta_{\text {medium }}=0.168, p<.01, \beta_{\text {high }}$ $=0.349, p<.001$.

Since the inverted classroom approach requires a major shift in student attitudes and behaviors towards their learning, these results show that the degree of engagement with the process is an important metric to consider.

Keywords: Inverted classroom, active learning, student engagement, learning styles

\section{INTRODUCTION}

Over the past 15 years the inverted classroom teaching approach has received increasing attention as instructors look for ways to enhance the active learning experience for their students. As the technology that can facilitate such an approach becomes more accessible, more instructors are experimenting with the inverted classroom. As this happens, there is also increasing interest in identifying what components of this approach are most beneficial and assessing its effects on student cognitive and affective outcomes.

For the most part, much of the discussion in the literature around this approach has focused on student and instructor perceptions rather than rigorous analysis of effects on outcome. Much of the research has indicated that student reactions are positive, but mixed [1] [2].

In terms of learning outcomes, there have also been conflicting reports in the literature. A group from the Computer Science Department at the University of Toronto observed an $8 \%$ increase in final exam performance after moving to an inverted model of teaching in their introductory programming course [3]. Despite the fact that the final exams were different between the two student cohorts, the authors report that an independent review of the exam questions by experts in the field showed that the two exams were of the same level of difficulty. However, others have reported that students in an inverted cohort performed worse on a common exam than a traditionallytaught cohort $(n=149$, average $=80.2 \%$ versus $83.7 \%$, with statistical significance) [4]. Many others have found no statistically significant difference between cohorts taught using an inverted approach versus a traditional didactic approach on common or very similar assessments [5] [6].

As of yet, little attention has been spent assessing any other types of outcomes with the inverted classroom model, such as the development of problem-solving, teamwork, or life-long learning skills. In an earlier paper, the authors reported that they found no effect on selfefficacy measures as it related to learning the course 
material, explaining the course concepts to others, and ability to succeed in an engineering program [7]. However, they also reported that confidence in problem-solving skills improved in their research study (see Table 1 below).

Why has the literature thus far present such a mixed view of this approach? One of the primary reasons is likely the difficulty in isolating the effects of the approach as a whole, despite the best efforts in study design. As well, the specifics of the approach vary quite dramatically amongst the published results ranging from a fully inverted experience in which little to no real lecturing takes place during the in-class time, to a more blended, active-learning method in which the instructors require pre-class preparation but run their "lectures" as a series of active learning experiences with periods of full-class lecturing through a review of the exercises. This demonstrates the importance within the literature of clearly defining the experience and the need for studies to begin to be more specific in their efforts to assess the unique aspects of the approach.

One of the other important aspects of the assessment of this approach is identifying the extent to which students are engaging with the inverted classroom as it was designed to be implemented by the course instructor. The primary purpose of this paper is to report on data associated with this question and answer the following two research questions:

1) Do students with different degrees of engagement with the inverted classroom approach exhibit different academic characteristics?, and

2) How does the degree of engagement affect the learning of the course material?

\section{BACKGROUND}

The data associated with this paper was collected over two years in the winter term of 2012 and 2013 in a secondyear core electrical and computer engineering physics course. The 2012 cohort was taught in a traditional lecturing approach and the 2013 cohort was taught with an inverted approach. Both cohorts were taught by the same instructor and all components of the courses (labs, tutorials, problem sets, assignments, etc.) were the same, only the inclass delivery and major assessments (midterm and final exam) were different.

It should be noted that the 2012 "traditional" approach did involve some active-learning components including the use of an in-class audience response system (e.g., clickers) as well as the use of tablet teaching to allow for the inclusion of applets, animations, videos, and the use of posted skeleton or outline notes for the students to bring with them to class to assist in note taking. The inverted approach also made use of these aspects (i.e., tabletteaching, in-class audience response systems, and skeleton notes).
The major difference between the two deliveries was that the inverted cohort was asked to watch a 15-30 minute lesson video before coming to class and the in-class time was used for more significant active-learning experiences such as peer instruction, think/pair/share, and collaborative problem-solving exercises. To encourage engagement with the new process students were given up to $7 \%$ of their course mark for "course participation," which was a combination of completion of the pre-class viewing quizzes that were embedded in the lesson videos and inclass participation. A typical lecture with the inverted cohort involved a short 3-5 minute recap of the associated lesson video key points and alternating periods of student activity and full-class lecturing in which the exercises and student misconceptions and errors, which were identified during the activities, were reviewed.

The traditional cohort had 310 students enrolled, while the inverted cohort had 338 students enrolled. Approximately $3 \%$ of the enrolled students did not complete the course, resulting in sample sizes of 299 and 329 for the two cohorts, respectively.

\section{STUDY METHODOLOGY}

A description of the primary variables associated with these research questions are summarized below in Table 1, along with a summary of their descriptive statistics.

In terms of the cohort characteristics prior to the start of the course, these descriptive statistics indicate that the two cohorts had very similar measures of prior academic performance, learning style profiles, and prior understanding of the course material as assessed by the preinstruction concept inventory test.

\section{RESULTS}

\subsection{Engagement with the Inverted Classroom Approach}

Two measures were used to assess the degree to which each student engaged with the inverted approach as it was designed for this course: lesson video viewing and lecture attendance. While these are not direct measures of the extent to which a student absorbed the lesson video content or participated with the in-class activities, they are reasonable proxies for this preliminary work.

Table 2 summarizes the video viewing and class attendance behaviours for the inverted cohort. About onefifth $(21 \%)$ of the class were deemed to be significantly engaged with this process by having watched more than $75 \%$ of the pre-class videos and attended more than $75 \%$ of the lectures. One-quarter $(26 \%)$ was more or less disengaged from the process by being below $50 \%$ in both categories, while about one-half (46\%) participated in more than half of these experiences. 
Table 1: Summary of Descriptive Statistics of Major Variables

\begin{tabular}{|c|c|c|c|c|c|}
\hline \multirow{2}{*}{ Variables } & \multirow{2}{*}{ Definitions and Measurements } & \multicolumn{2}{|c|}{ Traditional Cohort (2012) } & \multicolumn{2}{|c|}{ Inverted Cohort (2013) } \\
\hline & & $\mathbf{n}$ & Mean (SD) or \% & $\mathbf{n}$ & Mean (SD) or \% \\
\hline $\begin{array}{l}\text { Prior academic } \\
\text { performance }\end{array}$ & $\begin{array}{l}\text { Average grades for students' first } 15 \\
\text { courses completed in their first three terms. } \\
\text { Measuring their academic performance } \\
\text { prior to attending the course. }\end{array}$ & 151 & $73.4 \%(9.30)$ & 203 & $73.7 \%(9.36)$ \\
\hline $\begin{array}{l}\text { Learning style } \\
\text { assessment } \\
\text { (Index of } \\
\text { Learning Styles) }\end{array}$ & $\begin{array}{l}\text { Students' learning style: Reflective } \\
\text { Students' learning style: Intuitive } \\
\text { Students' learning style: Verbal } \\
\text { Students' learning style: Global }\end{array}$ & 266 & $\begin{array}{l}52.6 \% \\
39.9 \% \\
20.7 \% \\
40.2 \% \\
\end{array}$ & 280 & $\begin{array}{l}57.1 \% \\
37.5 \% \\
18.9 \% \\
38.2 \% \\
\end{array}$ \\
\hline $\begin{array}{l}\text { Lecture } \\
\text { attendance }\end{array}$ & $\begin{array}{l}\text { Percentage of the lectures attended. } \\
\text { Measuring student academic engagement. }\end{array}$ & 299 & $59.8 \%(24.9)$ & 326 & $59.5 \%(27.5)$ \\
\hline $\begin{array}{l}\text { Lesson video } \\
\text { viewing }\end{array}$ & $\begin{array}{l}\text { Percentage of the lesson videos for which a } \\
\text { student watched at least } 70 \% \text { prior to } \\
\text { attending the associated lecture. }\end{array}$ & & N.A. & 329 & $55.4 \%(26.1)$ \\
\hline $\begin{array}{l}\text { Concept } \\
\text { inventory: } \\
\text { Pre-test score }\end{array}$ & $\begin{array}{l}\text { Pre-test scores in percentage. } \\
\text { Measuring student conceptual } \\
\text { understanding of the course material at the } \\
\text { beginning of the course. }\end{array}$ & 287 & $46.3 \%(15.5)$ & 316 & $46.6 \%(15.3)$ \\
\hline $\begin{array}{l}\text { Concept } \\
\text { inventory: Post- } \\
\text { test score }\end{array}$ & $\begin{array}{l}\text { Post-test scores in percentage. } \\
\text { Measuring student conceptual } \\
\text { understanding at the end of the course. }\end{array}$ & 286 & $51.5 \%(19.0)$ & 314 & $50.5 \%(18.3)$ \\
\hline $\begin{array}{l}\text { Analytic } \\
\text { problem-solving } \\
\text { capabilities } \\
\text { (out of } 10 \text { ) } \\
\end{array}$ & $\begin{array}{l}\text { Averaged scores of four in-class quizzes for } \\
\text { students who wrote all four quizzes. The } \\
\text { full score for each quiz was } 10 . \\
\text { Measuring student analytic problem- } \\
\text { solving capabilities. }\end{array}$ & 129 & $4.65(1.79)$ & 114 & $6.20(1.75)^{* * *}$ \\
\hline $\begin{array}{l}\text { Confidence in } \\
\text { analytic } \\
\text { problem-solving } \\
\text { capabilities } \\
\text { (out of } 10 \text { ) } \\
\end{array}$ & $\begin{array}{l}\text { Averaged scores of all confidence ratings } \\
\text { for those students who wrote all four } \\
\text { quizzes. The scale was } 1 \text { to } 10 \text {. } \\
\text { Measuring student self-reported confidence } \\
\text { in resolving certain problems. }\end{array}$ & 129 & $3.47(1.44)$ & 114 & $4.60(1.71)^{* * *}$ \\
\hline $\begin{array}{l}\text { End-of-term } \\
\text { student survey }\end{array}$ & $\begin{array}{l}\text { The survey data measured (1) student } \\
\text { satisfaction with the course; (2) student } \\
\text { perception of the frequency and quality of } \\
\text { faculty-student interactions; (3) student } \\
\text { engagement; and (4) student sense of self- } \\
\text { confidence (i.e., self-efficacy) in studying } \\
\text { the course and engineering. }\end{array}$ & 167 & & 177 & \\
\hline $\begin{array}{l}\text { Course } \\
\text { academic } \\
\text { performance }\end{array}$ & Students' final grades in the course. & 299 & $70.4 \%(13.7)$ & 329 & $73.4 \% * * *(13.1)$ \\
\hline
\end{tabular}

$* * * p<.001$ 
Table 2: Relationship Between Video Viewing and Class Attendance for the Inverted Cohort

\begin{tabular}{||c|cccc|c|c||}
\hline & \multicolumn{7}{|c|}{ Class attendance } & & Percent of \\
Video Viewing & $\begin{array}{c}\text { Below } \\
\text { Cohort }\end{array}$ & $\mathbf{2 5 \% - 4 9 \%}$ & $\mathbf{5 0 \% - 7 4 \%}$ & $\begin{array}{c}\mathbf{7 5 \%} \text { and } \\
\text { above }\end{array}$ & $\begin{array}{c}\boldsymbol{n} \\
\text { (Viewing) }\end{array}$ \\
\hline Below 25\% & $6 \%$ & $2 \%$ & $2 \%$ & $1 \%$ & $12 \%$ & 40 \\
$\mathbf{2 5 \% - 4 9 \%}$ & $5 \%$ & $9 \%$ & $8 \%$ & $3 \%$ & $25 \%$ & 82 \\
$\mathbf{5 0 \% - 7 4 \%}$ & $2 \%$ & $6 \%$ & $14 \%$ & $12 \%$ & $34 \%$ & 112 \\
$\mathbf{7 5 \%}$ and above & $0 \%$ & $3 \%$ & $4 \%$ & $21 \%$ & $28 \%$ & 92 \\
\hline Percent of Cohort & $13 \%$ & $21 \%$ & $29 \%$ & $38 \%$ & $100 \%$ & \\
\hline $\boldsymbol{n}$ (Attendance) & 42 & 67 & 94 & 123 & & \\
\hline
\end{tabular}

Table 3: K-Mean Inverted Classroom Engagement Cluster Analysis - Descriptive Statistics

\begin{tabular}{|c|c|c|c|c|c||}
\hline \multirow{2}{*}{ Engagement Cluster } & \multirow{2}{*}{$\boldsymbol{N}$} & Lesson Video Viewing & \multicolumn{2}{c|}{ Lecture Attendance } \\
\cline { 3 - 5 } & & Mean & St. Dev. & Mean & St. Dev. \\
\hline Low Engagement & 93 & $30.0 \%$ & $18.1 \%$ & $25.6 \%$ & $15.0 \%$ \\
\hline Medium Engagement & 132 & $52.7 \%$ & $16.4 \%$ & $62.5 \%$ & $15.0 \%$ \\
\hline High Engagement & 101 & $83.1 \%$ & $11.3 \%$ & $87.0 \%$ & $10.5 \%$ \\
\hline
\end{tabular}

In order to better separate the entire cohort into groups of low, medium, and high engagement a statisticallyvalidated $k$-mean cluster analysis was performed. The clustering resulted in three similar sized groups with the high and low engagement groups having an average class attendance and video viewing about one standard deviation above or below the average for the cohort. The relevant descriptive statistics for each cluster is shown in Table 3.

\subsection{Student Characteristics of Engagement Clusters}

To address the first research question, a more careful analysis of the student characteristics was conducted. The characteristics that were assessed were prior academic performance (i.e., academic ranking at the start of the course), the three self-efficacy factors, and learning style.

Table 4 shows that there were statistically significant differences between the average prior academic performances of the three engagement groups, $F(2,200)=$ $14.5, p<.001$. As would be expected, the academically stronger students in the course prepared for class and came to class more often than those that had not performed as well in the previous three terms of the engineering program. No statistically-significant difference was found in any of the three self-efficacy factors between the groups. Indeed, these self-reported ratings are all reasonably high.

A measure of the student's learning style was determined by asking the students to self-report their Felder-Silverman Index of Learning Styles (ILS) score after they completed the 44-question online survey [8] [9]. The results for the different engagement groups are presented in Table 5.
Through Pearson Chi-Squared tests, the only ILS profile differences that were statistically significant were those related to the Active/Reflective and Intuitive/Sensing domains ( $p<.05$ for both cases.) It appears that the low and high engagement groups exhibit a predominantly active characteristics, while the medium engagement group is more balanced. As well, the high engagement group demonstrates a preference for a sensing learning style, meaning they are more concrete thinkers and appreciate learning through facts and specific procedures [10]. While the lower engagement groups seem to exhibit more intuitive learners, whom are more interested in learning from a theoretical approach and understanding the underlying relationships between things [10]. While not shown to be statistically significant, it is worth noting the difference in the Global/Sequential profiles. The high engagement group appears to learn best by following a series of clearly defined steps as opposed to starting from the larger picture and then discovering how the small pieces fit together into the great whole.

In some ways these preferences make sense given the fact that membership within the three groups appears to be primarily driven by prior academic performance. Students that succeed in a traditional lecture-based learning environment often demonstrate preferences for reflective, sensing, and sequential approaches [11]. 
Table 4: Prior Academic Performances and Self-Efficacy Factors for the Engagement Clusters

\begin{tabular}{|c|c|c|c|c|c|c|c|c|c|c|c|c|}
\hline \multirow[t]{2}{*}{$\begin{array}{l}\text { Engagement } \\
\text { Cluster }\end{array}$} & \multicolumn{3}{|c|}{$\begin{array}{l}\text { Prior Academic } \\
\text { Performance }\end{array}$} & \multicolumn{3}{|c|}{$\begin{array}{c}\text { Self-Efficacy Factor 1: } \\
\text { Explaining the Course } \\
\text { Concepts to Others } \\
\text { (scale out of 7) }\end{array}$} & \multicolumn{3}{|c|}{$\begin{array}{c}\text { Self-Efficacy Factor 2: } \\
\text { Learning the Course } \\
\text { Material } \\
\text { (scale out of 7) }\end{array}$} & \multicolumn{3}{|c|}{$\begin{array}{l}\text { Self-Efficacy Factor 3: } \\
\text { Studying Engineering } \\
\text { (scale out of 7) }\end{array}$} \\
\hline & $N$ & Mean & St. Dev. & $n$ & Mean & $\begin{array}{l}\text { St. } \\
\text { Dev. }\end{array}$ & $n$ & Mean & St. Dev. & $n$ & Mean & $\begin{array}{l}\text { St. } \\
\text { Dev. }\end{array}$ \\
\hline $\begin{array}{c}\text { Low } \\
\text { Engagement }\end{array}$ & 37 & $69.8 \%$ & $8.9 \%$ & 13 & 4.21 & 1.21 & 14 & 4.99 & 1.13 & 13 & 4.97 & 1.52 \\
\hline $\begin{array}{c}\text { Medium } \\
\text { Engagement }\end{array}$ & 85 & $71.7 \%$ & $8.6 \%$ & 71 & 4.35 & 1.35 & 72 & 5.09 & .95 & 69 & 5.04 & 1.00 \\
\hline $\begin{array}{c}\text { High } \\
\text { Engagement }\end{array}$ & 79 & $77.8 \%$ & $9.0 \%$ & 85 & 4.53 & 1.25 & 86 & 5.38 & .89 & 83 & 5.27 & .99 \\
\hline
\end{tabular}

Table 5: Learning Style Characteristics for the Engagement Clusters

\begin{tabular}{|c|c|c|c|c|c|c|c|c|c|}
\hline \multirow{2}{*}{$\begin{array}{l}\text { Engagement } \\
\text { Cluster }\end{array}$} & \multicolumn{9}{|c|}{ Index of Learning Style } \\
\hline & $\bar{n}$ & Reflective & Active & Intuitive & Sensing & Verbal & Visual & Global & Sequential \\
\hline $\begin{array}{c}\text { Low } \\
\text { Engagement }\end{array}$ & 79 & $63.3 \%$ & $36.7 \%$ & $49.4 \%$ & $50.6 \%$ & $24.1 \%$ & $75.9 \%$ & $44.3 \%$ & $55.7 \%$ \\
\hline $\begin{array}{c}\text { Medium } \\
\text { Engagement }\end{array}$ & 113 & $47.8 \%$ & $52.2 \%$ & $35.4 \%$ & $64.6 \%$ & $13.3 \%$ & $86.7 \%$ & $40.7 \%$ & $59.3 \%$ \\
\hline $\begin{array}{c}\text { High } \\
\text { Engagement }\end{array}$ & 87 & $63.2 \%$ & $36.8 \%$ & $29.9 \%$ & $70.1 \%$ & $21.8 \%$ & $78.2 \%$ & $29.9 \%$ & $70.1 \%$ \\
\hline
\end{tabular}

Table 6: Learning Outcomes for the Engagement Clusters

\begin{tabular}{|c|c|c|c|c|c|c||}
\hline \multirow{2}{*}{$\begin{array}{c}\text { Engagement } \\
\text { Cluster }\end{array}$} & \multicolumn{3}{|c|}{$\begin{array}{c}\text { Concept Inventory } \\
\text { Post-Test }\end{array}$} & \multicolumn{3}{c||}{ Final Course Mark } \\
\cline { 2 - 7 } & $\boldsymbol{n}$ & Mean & St. Dev. & $\boldsymbol{n}$ & Mean & $\begin{array}{c}\text { St. } \\
\text { Dev. }\end{array}$ \\
\hline $\begin{array}{c}\text { Low } \\
\text { Engagement }\end{array}$ & 83 & $46.7 \%$ & $17.7 \%$ & 93 & $63.5 \%$ & $11.0 \%$ \\
\hline $\begin{array}{c}\text { Medium } \\
\text { Engagement }\end{array}$ & 130 & $49.5 \%$ & $18.0 \%$ & 132 & $74.0 \%$ & $11.6 \%$ \\
\hline $\begin{array}{c}\text { High } \\
\text { Engagement }\end{array}$ & 100 & $54.8 \%$ & $18.5 \%$ & 101 & $81.8 \%$ & $10.2 \%$ \\
\hline \hline
\end{tabular}

\subsection{Learning Outcome Measures for Engagement Clusters}

An analysis of two of the major measures of learning outcomes in the course, the post-instruction concept inventory test and the final course mark, was carried out in order to address the second research question.

In table 6 it can be seen that differences were observed between the three engagement groups, and these were significant for both measures, $F_{\text {CIPost }}(2,310)=4.88, p<.01$ and $F_{\text {FinalGrade }}(2,323)=67.4, p<.001$.

These results are not surprising given that the academic strength of the students correlates well with engagement.
To better understand the effects of degree of engagement on the learning outcomes for the course, further regression analysis was performed.

A regression model was developed which had the final course mark as the dependent variable with the predictors consisting of learning styles (all domains), prior academic performance, and medium and high degrees of engagement. This meant that the comparison was against those in the low engagement group.

The model was found to be statistically-significant, $F(7,164)=52.8, p<.001$, with the model explaining $69.3 \%$ of the variance in the final course mark. Table 7 summarizes the results of this analysis. 
Table 7: Standardized and Unstandardized Coefficients of Predictors for Final Course Mark

\begin{tabular}{|c|c|c|c|c|}
\hline Predictors & $\begin{array}{c}\text { Unstandardized } \\
\text { Coefficients }\end{array}$ & $\begin{array}{c}\text { Standardized } \\
\text { Coefficient }(\beta)\end{array}$ & $t$ & $p$ \\
\hline Prior Academic Performance*** & .95 & .719 & 15.3 & .000 \\
\hline Learning Styles: Reflective & -1.27 & -.052 & -1.08 & .281 \\
\hline Learning Styles: Intuitive & 2.23 & .088 & 1.80 & .074 \\
\hline Learning Styles: Verbal & .049 & .002 & .036 & .972 \\
\hline Learning Styles: Global & 1.49 & .060 & 1.29 & .197 \\
\hline Medium Engagement** & 4.17 & .168 & 2.72 & .007 \\
\hline High Engagement*** & 8.69 & .349 & 5.33 & .000 \\
\hline
\end{tabular}

The most significant predictor is prior academic performance $(\beta=0.72)$, which indicate that for every $1 \%$ increase in prior academic performance the final course mark would increase by $0.95 \%$. However, these results also show that increasing degrees of engagement are also significant predictors for higher final course when prior academic performance and learning styles are controlled for, or kept "constant". Indeed, it would be expected that if a student moved from the low to high engagement group, their final mark, on average, would increase by $8.7 \%$, despite their learning style or level of prior academic performance.

\section{CONCLUSIONS}

The inverted classroom approach has potential to improve the teaching and learning experience within higher education due to the fact that it rests of sound educational principles by promoting more active and collaborative learning. Thus far, the assessment of this approach has produced mixed results relating to student perceptions and learning outcomes. Possible reasons for this is that the specifics of the implementation of this approach can vary and the studies in the literature has not accounted for the degree to which students participate in the approach as it was designed to be used.

This paper presents some preliminary results associated with the extent of student engagement with the inverted classroom approach and how this relates to the student characteristics and learning outcomes. The engagement with the approach was measured through a combination of the students' frequency of pre-class video viewing and class attendance.

It was found that when clustered into groups of low, medium, and high engagement, the clusters demonstrated significantly different degrees of prior academic performance, with $M_{\text {high }}=77.8 \%, M_{\text {medium }}=71.7 \%, M_{\text {low }}=$ $69.8 \%, F(2,198)=14.5, p<.001$. As well, the students in the medium and high engagement clusters demonstrated increasing degrees of preferences for a sensing or procedural-based learning style.
The results also demonstrated that students increased levels of engagement resulted in improved performance in two measures of learning outcomes, a post-instruction concept inventory test, and the final course marks. Further regression analysis also demonstrated that when prior academic performance and learning styles were controlled for, increasing degrees of engagement through higher frequencies of pre-class video viewing and in-class attendance, resulted in increasing degrees of final course grades. Indeed, if a student "moved" from the low to the high engagement group, the average expected change to their final course grade would be $8.7 \%$, or nearly an entire letter grade.

If engagement with the inverted classroom approach is in fact a significant predictor of positive impact on student learning outcomes, then how can students be encouraged to participate fully in this approach? This is an important question and the results presented here demonstrate how it vital it that this be addressed by instructors that are using this new teaching method. Efforts to justify the approach for students using pedagogical theory and educational research results is necessary as is some degree of extrinsic motivation, such as grades. However, more important than these things is the overt support in helping students make the significant shift that is required in their attitudes and behaviors towards their learning. Being explicit about the development of sound life-long learning skills as an additional outcome for courses using the inverted classroom approach will work to enhance the overall effectiveness of this kind of teaching and learning experience.

\section{References}

[1] M. Lage, G. Platt and M. Treglia, "Inverting the classroom: A gateway to creating an inclusive learning environment," Journal of Economic Education, vol. 31, no. 1, pp. 30-43, 2000.

[2] J. L. Bishop and M. A. Verleger, "The Flipped Classroom: A Survey of the Research," in Proceedings of 2013 ASEE Annual Conference \& Exposition, Atlanta, GA, 2013. 
[3] D. Horton, M. Craig, J. Campbell, P. Gries and D. Zingaro, "Comparing outcomes in inverted and traditional CS1," in Proceedings of the 2014 Conference on Innovation \& Technology in Computer Science Education (ITiCSE '14), Uppsala, Sweden, 2014.

[4] C. J. McClelland, "Flipping a Large-enrollment Fluid Mechanics Course - Is it Effective?," in Proceedings of 2013 ASEE Annual Conference \& Exposition, Atlanta, GA, June 2013.

[5] N. Lape, R. Levy, D. Yong, K. Haushalter, R. Eddy and N. Hankel, "Probing the Inverted Classroom: A Controlled Study of Teaching and Learning," in Proceedings of 2014 ASEE Annual Conference \& Exposition, Indianapolis, IN, 2014.

[6] B. Love, A. Hodge, N. Grandgenett and A. W. Swift, "Student Learning and Perceptions in a Flipped Linear Algebra Course," International Journal of Mathematical Education in Science and Technology, vol. 45, no. 3, 2013.

[7] M. Stickel, Q. Liu and S. Hari, "The Effect of the Inverted Classroom Teaching Approach on Student/Faculty Interaction and Students' Self-Efficacy," in Proceedings
2014 ASEE Annual Conference \& Exposition, Indianapolis, IN, June 2014.

[8] R. M. Felder and B. A. Soloman, "Index of Learning Styles Questionnaire," [Online]. Available: http://www.engr.ncsu.edu/learningstyles/ilsweb.html. [Accessed 14 March 2014].

[9] "Index of Learning Styles," [Online]. Available: http://www4.ncsu.edu/unity/lockers/users/f/felder/public/I LSdir/styles.htm. [Accessed 17 April 2015].

[10] R. M. Felder and J. Spurlin, "Applications, Reliability and Validity of the Index of Learning Styles," International Journal of Engineering Education, vol. 21, no. 1, pp. 103112, 2005.

[11] T. A. Litzinger, S. H. Lee, J. C. Wise and R. M. Felder, "A Psychometric Study of the Index of Learning Styles@," Journal of Engineering Education, vol. 96, no. 4, pp. 309-319, 2007. 